九州大学学術情報リポジトリ

Kyushu University Institutional Repository

\title{
Ticks from Wild Mammals in the Kyushu District Including Okinawa Prefecture, Japan
}

Kakuda, Hiroyuki

Zoological Laboratory, Faculty of Agriculture, Kyushu University

Shiraishi, Satoshi

Zoological Laboratory, Faculty of Agriculture, Kyushu University

Uchida, Teruaki

Zoological Laboratory, Faculty of Agriculture, Kyushu University

https://doi.org/10.5109/23938

出版情報 : 九州大学大学院農学研究院紀要. 33 (3/4)，pp.267-273，1989-03. Kyushu University バージョン：

権利関係: 


\title{
Ticks from Wild Mammals in the Kyushu District Including Okinawa Prefecture, Japan
}

\author{
H iroyuki Kakuda, Satoshi Shiraishi* and Teru Aki Uchida \\ Zoological Laboratory, Faculty of Agriculture, \\ Kyushu University 46-06, Fukuoka 812, Japan.
}

(Received November 4, 1988)

\begin{abstract}
As a part of ecological studies on ticks, various kinds of ticks from wild mammals collected in the Kyushu district including Okinawa Prefecture, Japan were surveyed from 1982 to 1988. Nine tick species consisting of Argas vespertilionis, Amblyomma testudinarium, Haema. physalis flava, H.megaspinosa, H. phasiana, H. Iongicomis, H. hystricis, Ixodes ovatus and I. nipponensis (329 ticks in total), were captured from 15 species of mammals. As for the argasids, the larva of $\mathbf{A}$. vespertilionis alone was obtained from the two Japanese house bats. The majority of the ticks were H. Alava and $I$. nipponensis, taken from various kinds of mammals, suggesting that both tick species had a wide host range as does I. ovatus. Both $I$. ovatus and I. nipponensis showed a different host preference between the immature and the adult stages.
\end{abstract}

\section{INTRODUCTION}

Ticks feeding on vertebrate's blood are of medical and veterinary importance, because they are vectors for various diseases, not to mention the fact that they directly harm hosts by attachment. In particular, the cattle tick, Haemaphysalis Zongicornis does much damage to animal husbandry as the vector for theileriosis caused by Theileria sergenti. The tick life cycle seems closely associated with wild mammals. Knowledge of life cycles and host associations of ticks is therefore essential in studying the tick-borne diseases and tick-control efforts. In Japan, there have been a few studies on their life cycles, except for H. Zongicornis (Namba, 1958 ; Yoshida, 1975, 1980 ; Chikaki, 1976). However, several reports on host-tick relationships have been published (Saito, 1959 ; Yamaguti et al., 1971; Kitaoka and Suzuki, 1974 ; Takada and Yamaguchi, 1974 ; Kitaoka et al., 1975 ; Fujita et al., 1981 ; Fujimoto et al., 1986).

As a basis for ecological studies on ticks, host-tick relationships are considered important. Therefore, a survey of ticks from wild mammals collected in the Kyushu district including Okinawa Prefecture was carried out from 1982 to 1988.

\section{MATERIALS AND METHODS}

The localities of tick-infested wild mammals were shown in Fig. 1. In order to find ticks, each animal was carefully examined upon visual inspection or under a binocular microscope. Most of the ticks from medium- to large-sized mammals were obtained

*To whom reprint requests should be addressed. 


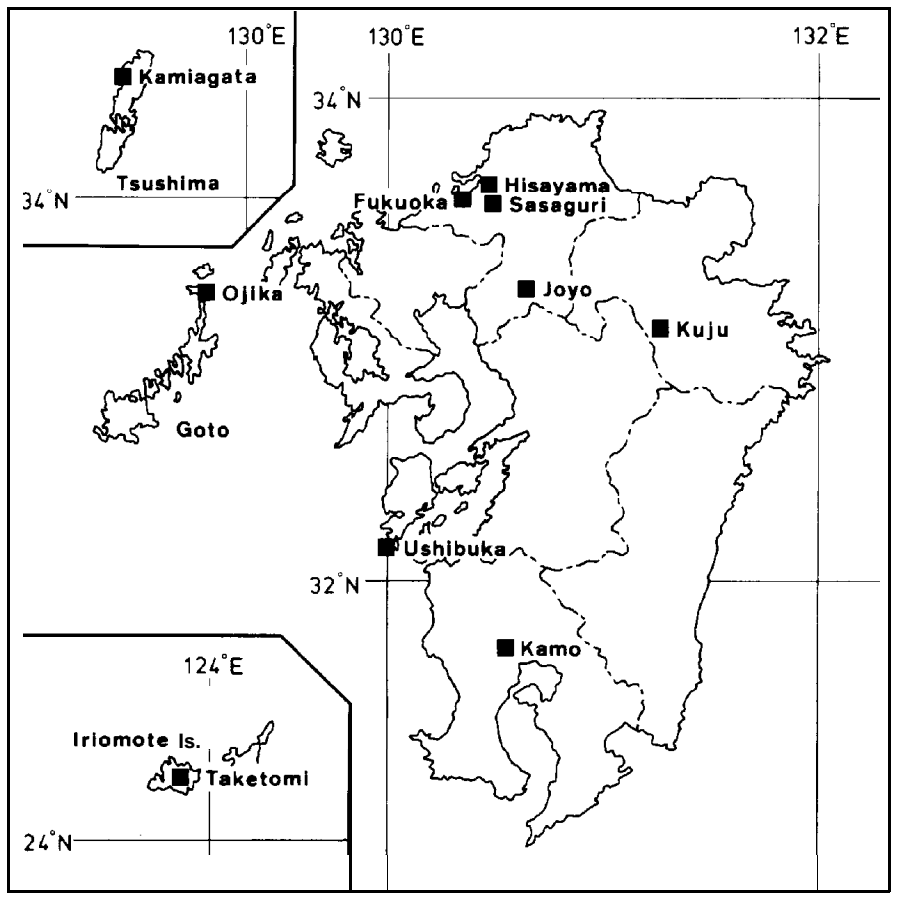

Fig. 1. Map showing the localities where host mammals were collected.

through the courtesy of other workers. Ticks were preserved in $70 \%$ ethanol and examined in a binocular microscope or a scanning electron microscope.

\section{RESULTS}

A total of 329 ticks obtained, consisting of Argas vespertilionis (Argasidae), A mblyomma testudinarium, Haemaphysalis flava, $\mathbf{H}$. megaspinosa, $\mathbf{H}$. phasiana, $\mathbf{H}$. longicornis, H. hystricis, Ixodes ovatus and I. nipponensis (Ixodidae), were listed according to the species (Table 1). In accordance with the host mammals (the number in parentheses), the Japanese shrew, Crocidura dsinezumi (3) (Insectivora: Soricidae) ; Japanese greater shrew-mole, Urotrichustalpoides (1) (Talpidae) ; Japanese house bat, Pipistrellus abramus (2) (Chiroptera : Vespertilionidae) ; Japanese (Kyushu) hare, Lepus brachyurus brachyurus (7) ; feral domestic rabbit, Oryctolagus cuniculus domes. tica (2) (Lagomorpha : Leporidae) ; Smith's red-backed vole, Eothenomys smithii (1) ; Japanese field vole, Microtus montebelli (1); Japanese larger field mouse, Apodemus speciosus (4) ; Japanese lesser field mouse, A podemus argenteus (1) (Rodentia : Muridae) ; Tsushima yellow marten, Martes melampus tsuensis (6) ; Korean weasel, Mustela sibirica coreana (7) (Carnivora : Mustelidae) ; Iriomote cat, Mayailurus iriomotensis (8) ; leopard cat, Felis bengalensis manchurica (4) (Felidae) ; Japanese wild hog, Sus scrofa leucomystax (1) (Artiodactyla : Suidae) and Kyushu shika deer, Cervus nippon nippon (1) (Cervidae) (49 individuals of 15 species, 14 genera, 9 families belonging to 6 orders in total) were examined. 
The larvae of Argas vespertilionis were obtained from the two Japanese house bats. The fact that the larva and/or nymph of Ixodes (I. ovatus and I. nipponensis) were taken mainly from small-sized mammals and the adult from medium-sized

Table 1. Ticks obtained from mammals in the Kyushu district including Okinawa Prefecture.

\begin{tabular}{|c|c|c|c|c|c|c|c|}
\hline \multirow{2}{*}{ Tick species } & \multicolumn{4}{|c|}{ Number of ticks* } & \multirow{2}{*}{$\begin{array}{l}\text { Host } \\
\text { speciest }\end{array}$} & \multirow[b]{2}{*}{ Locality } & \multirow{2}{*}{ Prefecture } \\
\hline & $\mathrm{L}$ & $\mathrm{N}$ & & 우 & & & \\
\hline \multicolumn{8}{|l|}{ Argasidae } \\
\hline $\begin{array}{l}\text { Argas } \\
\text { vespertilionis }\end{array}$ & 20 & 0 & & 0 & & Fukuoka & Fukuoka \\
\hline \multicolumn{8}{|l|}{ Ixodidae } \\
\hline \multicolumn{8}{|l|}{ A mblyomma } \\
\hline \multicolumn{8}{|l|}{ Haemaphysalis } \\
\hline \multirow[t]{6}{*}{ flava } & 0 & 3 & 1 & 0 & LB (1) & Hisayama & Fukuoka \\
\hline & 0 & 25 & 16 & 7 & LB (4) & Kamo & Kagoshima \\
\hline & 1 & 0 & 0 & 0 & $\mathrm{AA}(1)$ & Hisayama & Fukuoka \\
\hline & 0 & 1 & 0 & 0 & MT (1) & Kamiagata & Nagasaki \\
\hline & 0 & 5 & 0 & 0 & MS (3) & Kamiagata & Nagasaki \\
\hline & 0 & 0 & 1 & 9 & SS (1) & Joyo & Fukuoka \\
\hline megaspinosa & 0 & 1 & 0 & 2 & $\mathrm{CN}(1)$ & Ojika & Nagasaki \\
\hline \multirow{2}{*}{ phasiana } & 0 & 0 & 0 & 3 & $\mathrm{OC}_{(2)}$ & Ushibuka & Kumamoto \\
\hline & 0 & 1 & 0 & 0 & $\mathrm{CN}(1)$ & Ojika & Nagasaki \\
\hline \multirow[t]{3}{*}{ longicornis } & 0 & 6 & 0 & 0 & LB (1) & Hisayama & Fukuoka \\
\hline & 0 & 7 & 1 & 2 & LB (2) & Sasaguri & Fukuoka \\
\hline & 0 & 1 & 0 & 0 & MT (1) & Kamiagata & Nagasaki \\
\hline \multicolumn{8}{|l|}{$\begin{array}{l}\text { hys tricis } \\
\text { Ixodes }\end{array}$} \\
\hline \multirow{7}{*}{ ovatus } & 1 & 1 & 0 & 0 & $\mathrm{CD}(2)$ & Hisayama & Fukuoka \\
\hline & 4 & 0 & 0 & 0 & UT (1) & Hisayama & Fukuoka \\
\hline & 0 & 0 & 0 & 1 & LB (1) & Hisayama & Fukuoka \\
\hline & 2 & 1 & 0 & 0 & ES (1) & Hisayama & Fukuoka \\
\hline & 0 & 1 & 0 & 0 & $\mathrm{MM}(1)$ & Kuju & Oita \\
\hline & 6 & 3 & 0 & 0 & AS (4) & Hisayama & Fukuoka \\
\hline & 1 & 0 & 0 & 0 & AA (1) & Hisayama & Fukuoka \\
\hline \multirow[t]{7}{*}{ nipponensis } & 1 & 1 & 0 & 0 & $\mathrm{CD}(1)$ & Sasaguri & Fukuoka \\
\hline & 0 & 0 & 2 & 1 & LB (2) & Kamo & Kagoshima \\
\hline & 0 & 2 & 0 & 0 & AS (2) & Hisayama & Fukuoka \\
\hline & 0 & 1 & 0 & 0 & AA (1) & Hisayama & Fukuoka \\
\hline & 0 & 0 & 9 & 21 & MT (5) & Kamiagata & Nagasaki \\
\hline & 0 & 2 & 24 & 52 & MS (6) & Kamiagata & Nagasaki \\
\hline & 0 & 1 & 16 & 23 & FB (4) & Kamiagata & Nagasaki \\
\hline
\end{tabular}

${ }^{*} \mathrm{~L}$, larva; N, nymph; $\sigma^{7}$, adult male; of, adult female. ${ }^{\dagger} \mathrm{AA}, \mathrm{A}$ podemus argenteus; AS, Apodemus speciosus; CD, Crocidura dsinezumi ; CN, Cervus nippon nippon; ES, Eothenomys smithii ; FB, Felis bengalensis manchurica; LB, Lepus brachyurus brachyurus; MI, Mayailurus iriomotensis ; MM, Microtus montebelli ; MS, Mustela sibirica coreana ; MT, Martes melampus tsuensis ; OC, Oryctolagus cuniculus domestica (feral domestic rabbit) ; PA, Pipistrellus abramus; SS, Sus scrofa leucomystax ; UT, Urotrichus talpoides. The numbers of host mammals examined are in parentheses. 
mammals suggested a different tendency in host preference between the immature and the adult stages. On the contrary, Haemaphysalis ticks showed no such a tendency. I. nipponensis was so abundant that it constituted $50.5 \%$ of all ixodids collected, and was especially dominant on mammals from Tsushima (e. g. the Tsushima yellow marten, Korean weasel and leopard cat). H. flava had a broad host range and was next abundant, accounting for $22.3 \%$ of all ixodids captured. H.longicornis was obtained from three Japanese hares and one Tsushima yellow marten, but the number of that tick from the above wild mammals was much smaller than that from grazing cattle. H. megaspinosa and $H$. phasiana were few, both of which were taken from one Kyushu shika deer captured on Nozaki Is. of the Goto Isls., Nagasaki Pref. H. phusiana was collected also from feral domestic rabbits on Oshima Is. of Ushibuka City, Kumamoto Pref. A. testudinarium and $\mathbf{H}$. hystricis were obtained from the Iriomote cats on Iriomote Is., Okinawa Pref.

\section{DISCUSSION}

The majority of argasids exhibit the "multihost" life cycle. The sequence requires a separate host for the larva, each nymphal instar and each adult feeding. Adult argasids with this type of life cycle feed several times. In contrast with this, the three-host ixodids utilize a separate host for each developmental stage. The host-tick relationships are discussed separately according to the two tick families as follows.

\section{Argasidae}

Most argasid larvae require long feeding periods (several days), but most nymphs and adults complete feeding within minutes or a few hours (Asanuma, 1965) : the habitat of a soft tick, Argas vespertilionis may be bats or their roosting sites. The argasid tick sometimes infests humans (Kamimura and Kondo, 1977a), and the authors also collected two adult females from two persons in a house where the Japanese house bats roosted (Kakuda, unpublished).

\section{Ixodidae}

It has been well known that $\mathbf{H}$. phasiana and $\mathbf{H}$. Zongicornis exhibit host specificity. H. phasiana shows a distinct preference for birds, especially for pheasants (Yamaguti et al., 1971 ; Saito et al., 1974). Engorged, one nymph and three adult females of $\mathbf{H}$. phasiana, however, were first found from mammals, i. e. one Kyushu shika deer and two feral domestic rabbits, respectively, in the present survey.

H. longicornis is most dominant in Japanese pastures and selectively parasitises grazing cattle (Kitaoka, 1975 ; Kitaoka et al., 1975). This tick has been sometimes obtained from humans (Yamaguti, 1977 ; Yamaguti and Suzuki, 1981; Yamaguti and Takada, 1981) and the following various kinds of mammals : the Japanese (Kyushu) hare (this study), Japanese (Tohoku) hare, L.b. angustidens (Saito et al., 1965), Japanese black bear, Selenarctos thibetanus japonicus (Fujita and Takada, 1977 ; Takada and Fujita, 1978), dogs (Saito, 1978 ; To et al., 1980 ; Fujita et al., 1981), the Japanese raccoon dog, Nyctereutes procyonoides viverrinus (Saito et al., 1965), Tsu- 
shima yellow marten (this study), Japanese badger, Meles meles anakuma (Saito et al., 1965), Japanese wild hog (Saito, 1978 ; Kakuda, unpublished) and Honshu shika deer, C. n. centralis (Yamaguti et al., 1971). That is, H. Zongicornis has a broad host range, and the above wild mammals are regarded as the important temporary or substitute hosts filling the blank of cattle in completing the tick life cycle during the non-grazing period, suggesting epizootically the possible transmission of Theileria sergenti to such wild mammals. Correspondence of timing between the active season of $H$. Zongicornis and the grazing period may cause serious damage to cattle.

All the ticks collected, except for the two above-mentioned ticks, exhibit a wide host range. Both A. testudinarium and $H$. hystricis are common species in the Ryukyu Islands, and feed on the Ryukyu rabbit, Pentalagus furnessi, Ryukyu wild hog, S. s. riukiuanus, dogs (Kitaoka and Suzuki, 1974 ; Yamaguti et al., 1971) and the Iriomote cat (Hasegawa and Iwatsuki, 1986 ; this study). A. testudinarium frequently attaches to humans (Yamaguti et al., 1971; Yamamoto et al., 1976 ; Kamimura and Kondo, 1977b ; Yamaguti, 1977 ; Yamaguti and Takada, 1981; Kakuda, unpublished),

H. flava, which has been regarded as a vector for tularemia (Asanuma et al., 1956 ; Asanuma and Sakurai, 1958 ; Fujita et al., 1985), is widely distributed in Japan (Kitaoka, 1975), and has a very broad host range, including birds. In this study, however, only one larva of $H$. flava was collected from small-sized mammals (the Japanese lesser field mouse), suggesting that small-sized mammals are not important hosts for this tick (Fujita et al., 1981).

H. megaspinosa has been taken from the Yeso brown bear, Ursus arctos yesoensis, Japanese black bear (Kitaoka et al., 1975), Japanese wild hog (Yamaguti et al., 1971), Kyushu shika deer (Yamaguti et al., 1971; this study), Honshu shika deer and Japanese serow, Capricornis crispus crispus (Yamaguti et al., 1971). These large-sized mammals seem to be important hosts for this tick.

I. ovatus and I.nipponensis display a difference in host preference between the developmental stages, i. e. the immature and adult parasitise small- and medium-sized mammals, respectively. All the immatures of I. ovatus were obtained from small-sized fossorial mammals, supporting the assumption that the immature attaches to hosts in their tunnels (Asanuma, 1965). The immature of I. nipponensis commonly attacks the kanahebi lizard, Takydromus tachydromoides, which is a small-sized terrestrial reptile (Fujita and Takada, 1978; Yoneda, 1981; Fujimoto et al., 1986). On the other hand, the adults of both Ixodes species were taken from medium-sized mammals. In contrast to the adult, the immatures of these two species appear not to ascend vegetation. Judging from the above, it is revealed that such a difference in host preference between the immature and the adult stages may be due to the disparity in ascending behaviour.

Both the Tsushima yellow marten and the leopard cat are rare species. Accordingly, to our knowledge, this is the first record on ticks found from such mammals in Japan. Much of the host-tick relationships has remained unsolved. It is thus essential that further investigations of ticks from various wild animals are carried out in order to elucidate the relationship.

\section{ACKNOWLEDGEMENTS}

The authors wish to express their appreciation to Mr. A. Taniguchi, the former 
staff of Kagoshima Prefecture Forest Experiment Station and graduate students of Department of Biology, Faculty of Science, Kyushu University for giving us tick specimens; Dr. N. Yamaguti, Department of Parasitology, Saitama Medical School for identification of ticks from the Iriomote cat ; and Professor E. W. Jameson, Jr., University of California for comments on the manuscript. We would also like to thank Dr. T. Mōri and graduate students of our laboratory for collecting mammals and ticks throughout this study. This work was supported in part by a Grant-in-Aid from the Ministry of Education, Science and Culture, Japan.

\section{REFERENCES}

Asanuma, K. 1965 Ticks. In "Mites. An Introduction to Classification, Bionomics and Control of Acarina.“, ed. by M. Sasa, Univ. of Tokyo Press, Tokyo, pp. 101-128 (in Japanese)

Asanuma, K. and N. Sakurai 1958 On the seasonal occurrence of the tick, Haemaphysalis flava, on wild hares (Lepus timidusbrachyurus) in the endemic area of Yato-byo or tularemia in Chiba Prefecture, Japan (a preliminary note). Misc. Rep. Res. Inst. Natur. Resources, 48: 28-39 (in Japanese with English summary)

Asanuma, K., S. Ohara, N. Sakurai, H. Nakagawa, A. Goto and T. Sato 1956 Studies on ticks infesting source animals of Yato-byo or tularemia in Japan. Jpn. J. Sanit. Zool., 7: 127 (in Japanese)

Chikaki, H. 1976 Biological studies on Haemaphysalis longcornis. Special Reports of Insect Management Laboratory, Faculty of Agriculture, Shimane Univ., 1: 1-76 (in Japanese with English summary)

Fujimoto, K., N. Yamaguti and M. Takahashi 1986 Ecological studies on ixodid ticks. 1. Ixodid ticks on vegetations and wild animals at the low mountain zone lying southwestern part of Saitama Prefecture. Jpn. J. Sanit. Zool., 37: 325-331 (in Japanese with English summary)

Fujita, H. and N. Takada 1977 Studies on ixodid fauna in the northern part of Honshu, Japan. 4. Additional report on hosts and distribution of ixodid ticks (Ixodidae) and some cases of human infestation. Jpn. J. Sanit. Zool., $28: 57$ (in Japanese)

Fujita, H. and N. Takada 1978 Studies on ixodid fauna in the northern part of Honshu, Japan. 3. Preliminary notes on Ixodes nipponensis (Ixodoidea; Ixodidae) found on the small reptile, Takydromus tachydromoides. Jpn. J. Sanit. Zool., 29: 269-271

Fujita, H., H. Ootake and S. Ohara 1985 Isolation of Francisella tularensis from a tick Haemaphysalis flava parasitized on a dead hare and serologic survey on range cattle in Kawatabi Farm, Miyagi Prefecture, Japan. Jpn. J. Sanit. Zool., 36:75-77 (in Japanese with English summary)

Fujita, H., M. Takahashi, S. Yamamoto, T. Saito and K. Machida 1981 Ixodid ticks (Acarina : Ixodidae) parasitic on mammals and birds in Saitama Prefecture, Central Japan. 1. Host-tick relationships, geographical and vertical distributions, and medical problems. Ann. Rep. Ohara Hosp., 24 : 13-27 (in Japanese with English summary)

Hasegawa, H. and N. Iwatsuki 1986 Parasites of the Iriomote wildcat, Mayailumusiriomotensis (II). Island Studies in Okinawa, 4:1-7 (in Japanese with English abstract)

Kamimura, K. and K. Kondo 1977a Three cases of human infestation with a soft tick Argas vespertilionis s. 1. in Japan. Jpn.J. Sanit. Zool., 28: 248-249 (in Japanese)

Kamimura, K. and K. Kondo 1977b Four cases of human infestation with three tick species Amblyommatestudinarium, Ixodes nipponensa's and I. ovatus in Japan. Jpn. J. Sanit. Zool., 28:249250 (in Japanese)

Kitaoka, S. 1975 Cattle ticks and their distribution in Japan. Animal Husbandry, 29 : 1085-1088 (in Japanese)

Kitaoka, S. and H. Suzuki 1974 Reports of medico-zoological investigations in the Nansei Islands. 
Part 2. Ticks and their seasonal prevalences in southern Amami-oshima. Jpn. J. Sanit. Zool., 25 : 21-26 (in Japanese with English summary)

Kitaoka, S., T. Morii and K. Fujisaki 1975 Consideration on the grazing cattle-tick relationship in Japan, with special reference to large wild mammals and the deer-tick ecosystem in the Tanzawa Mountains. Bull. Nat. Inst. Anim. Hlth, 70: 35-42 (in Japanese)

Namba, N. 1958 Ecological studies on Haemaphysalis bispinosa, a harmful tick in the pasture of northern Japan. Hokkaido Nat. Agr. Exp. Stn. Rep., (50) : 1-99 (in Japanese with English r\&sum\&)

Saito, Y. 1959 Studies on ixodid ticks. Part I. On ecology, with reference to distribution and seasonal occurrence of ixodid ticks in Niigata Prefecture, Japan. Acta Med. Biol. 7 : 193-209

Saito, Y. 1978 Ixodid ticks in Awajishima Is., Japan. Jpn. J. Sanit. Zool., 29: 50 (in Japanese)

Saito, Y., H. Hoogstraal and H. Y. Wassef 1974 The Haemaphysalis ticks (Ixodoidea : Ixodidae) of birds. 4. H.(Ornithophysalis) phasiana sp. n. from Japan. J.Parasitol., 60 : 198-208

Saito, Y., M. Kubota, A. Yajima, T. Watanabe and K. Kamino 1965 Studies on ixodid ticks. Part VIII. On Haemaphysalis bispinosa Neumann, 1897 in Niigata Prefecture, Japan, with some supplementary observation on bovine piroplasmosis. Acta Med. Biol., 13: 143-159

Takada, N. and H. Fujita 1978 Studies on ixodid fauna in the northern part of Honshu, Japan. 4. An inclusive survey of the tick fauna during the past ten years. Ann. Rep. Ohara Hosp., $21: 19$ 34 (in Japanese with English summary)

Takada, N. and T. Yamaguchi 1974 Studies on ixodid fauna in the northern part of Honshu, Japan, 1. Ixodid ticks (Ixodidae) parasitic on wild mammals and some cases of human infestation. Jpn. J. Sanit. Zool., 25: 35-40 (in Japanese with English summary)

To, Y., S. Takahashi and T. Kifune 1980 Oviposition and development of eggs in Haemaphysalis longicornis. Jpn. J. Sanit. Zool., 31: 165 (in Japanese)

Yamaguti, N. 1977 Studies on cases of human infestation with ixodid ticks during the past fifty years. Jpn.J. Sanit. Zool. 28: 23 (in Japanese)

Yamaguti, N. and H. Suzuki 1981 Some rare cases of human infestation with ixodid ticks. Jpn. J. Sanit. Zool., 32: 171 (in Japanese)

Yamaguti, N. and N. Takada 1981 Thirty nine case reports of human infestation with ixodid ticks. Jpn.J.Sanit. Zool., 32 : 86-89 (in Japanese with English summary)

Yamaguti, N., V. J. Tipton, H. L. Keegan and S. Toshioka 1971 Ticks of Japan, Korea and the Ryukyu Islands. Brigham Young Univ. Sci. Bull. Biol.Ser., $15: l-226$

Yamamoto, S., H. Takaoka and J. Sameshima 1976 A case of human infestation with a hard tick Amblyommatestudinarium Koch (Acarina: Ixodidae), in Japan. Jpn. J. Sanit. Zool., 2'7: 304 (in Japanese)

Yoneda, Y. 1981 Additional report of Ixodes nipponensis found on the small reptile, Takydromus tachydromoides, in Kyushu. Jpn. J. Sanit. Zool., $32: 82-83$ (in Japanese with English summary)

Yoshida, T. 1975 Ecological studies for the control of the tick in the pasture. J.Fac. Liberal Arts, Shinshu Univ., 9: 27-111 (in Japanese with English summary)

Y oshida, T. 1980 Ecology of the tick, Haemaphysalis longicomis, in the pasture of Japan. Biological Science, $32: 1-10$ (in Japanese) 